\title{
Magnetic resonance spectroscopy in a patient with Kleine-Levin syndrome
}

\section{Journal Article}

Author(s):

Poryazova, R.; Schnepf, B.; Bösiger, Peter; Bassetti, C. L.

Publication date:

2007

Permanent link:

https://doi.org/10.3929/ethz-b-000005722

Rights / license:

In Copyright - Non-Commercial Use Permitted

Originally published in:

Journal of neurology 254(10), https://doi.org/10.1007/s00415-007-0531-x 
Rositsa Poryazova

Betina Schnepf

Peter Boesiger

Claudio L. Bassetti

\section{Magnetic resonance spectroscopy in a patient with Kleine-Levin syndrome}

Received: 18 September 2006

Received in revised form:

29 December 2006

Accepted: 16 January 2007

Published online: 15 October 2007

Sirs: Kleine-Levin syndrome (KLS) is a rare recurrent hypersomnia associated with behavioural, cognitive, eating and sexual disturbances $[1,2]$. A recent SPECT study in 7 patients with (KLS) showed decreased thalamic perfusion during the hypersomnolent attacks [3]. These findings were later confirmed in a case report by Hong et al. [4]. Proton magnetic resonance spectroscopy $\left({ }^{1} \mathrm{H}\right.$ MRS $)$ is a noninvasive method of obtaining metabolic information. By means of MRS, different compounds can be measured including $\mathrm{N}$-acetylaspartate (NAA), a marker of neuronal integrity and glutamate-glutamine (Glu-Gln), which plays an important role in excitatory neurotransmission and mitochondrial metabolism [5].

We present a 19-year-old patient with idiopathic, classical KLS. Over

\footnotetext{
R. Poryazova · Prof. Dr. C. L. Bassetti (赤)

Department of Neurology

University Hospital of Zurich

Frauenklinikstrasse 26

CH-8091 Zurich, Switzerland

Tel.: + 41-12555503

Fax: +41-12554649

E-Mail: claudio.bassetti@usz.ch

B. Schnepf · P. Boesiger

Institute for Biomedical Engineering

University and ETH Zurich

Gloriastrasse 35

8092 Zurich, Switzerland
}

a 4-year period he suffered 19 stereotypical hypersomnolent episodes. The attacks were always preceded or accompanied by fever up to $39^{\circ} \mathrm{C}$, sore throat or stomach pain. At the beginning of the episodes mood depression was observed, the patient was melancholic, sad and withdrew socially. Sleep behaviour reached 20 hours/day, interrupted by compulsive eating, 7-8/days without any specific food preference resulting in a weight gain of approximately 5 $\mathrm{kg} /$ attack. Sexual disinhibition with masturbation, irritability, aggressiveness, cognitive and concentration disturbances were frequent. The attacks usually ended with insomnia lasting 2-3 days and a subsequent gradual improvement of emotional state and cognition. The patient described this phase as awakening from a dream and had difficulty recalling the events that had occurred during the attack. In the first year before treatment 12 attacks were observed. Under therapy with lithium $30 \mathrm{mg} /$ day and valproic acid $2000 \mathrm{mg} /$ day a remarkable reduction in frequency and severity of the episodes ( 7 attacks over a period of 2.5 years) was noted. The duration of the hypersomnolent episodes remained unchanged, 10 days on average.

Hypocretin-1 in the cerebrospinal fluid during an attack was in the normal range, $530 \mathrm{pg} /$ $\mathrm{ml}$.

The patient underwent ${ }^{1} \mathrm{H}$ MRS in an asymptomatic period and a month later during a typical episode. Because of presumed hypothalamic [6] or thalamic $[3,4]$ dysfunction in KLS we chose three regions of interest: hypothalamus and both thalami. MRS was performed on a Philips Achieva 3.0 T scanner. Single-voxel proton MR spectra, voxels of $17 \times 14 \times 15 \mathrm{~mm}$ in both thalami $\left(3.57 \mathrm{~cm}^{3}\right)$ and of $10 \times 10 \times 10 \mathrm{~mm}\left(1 \mathrm{~cm}^{3}\right)$ in the hypothalamus, were acquired and processed to determine metabolite concentration ratios. A remarkable change between the two examinations was observed in the concentration ratios of NAA-NAAG, (total NAA)/Cr and Glu-Gln/Cr (Fig. 1).

During the attack lower (total NAA)/Cr ratios in the right $(-25.7 \%)$ and left $(-13.2 \%)$ thalami were observed. In the hypothalamus the (total NAA)/Cr ratio was slightly higher in the second scan during the hypersomnolent attack. The Glu-Gln/Cr ratio was higher during the attack - in both the right $(59.8 \%)$ and left $(52.3 \%)$ thalamus. In hypothalamus a reliable value for Glu-Gln/Cr ratio was obtained only during the second scan and it was similar to the values in both thalami.

Different values for intraindividual metabolite ratio, variability and reproducibility of the results are reported in the literature, depending on the technical parameters of the acquisition and on the region of interest. For example an intraindividual temporal cortical variation up to $12 \%$ was observed for (total NAA)/Cr and up to $29 \%$ for Glu-Gln/Cr on a 3T scanner [7]. The decrease in the (total NAA)/Cr concentration ratio in both thalami during the hypersomnolent episode in our patient exceeds the normal range of the intraindividual variability at $3 \mathrm{~T}$. Our finding supports the hypothesis of a thalamic dysfunction in KLS, recently suggested by other authors $[3,4]$. This hypothesis is indirectly supported also by the observation of KLS-similar symptoms (reduced alertness, impaired sleep and behavioural changes) following paramedian thalamic strokes [8]. The observed high Glu-Gln/Cr concentration ratio in all regions of interest during the episode points to additional, global metabolic changes in the brain. Glutamate is a primary excitatory neurotransmitter. Decreased NAA/Cr and increased 
Fig. 1
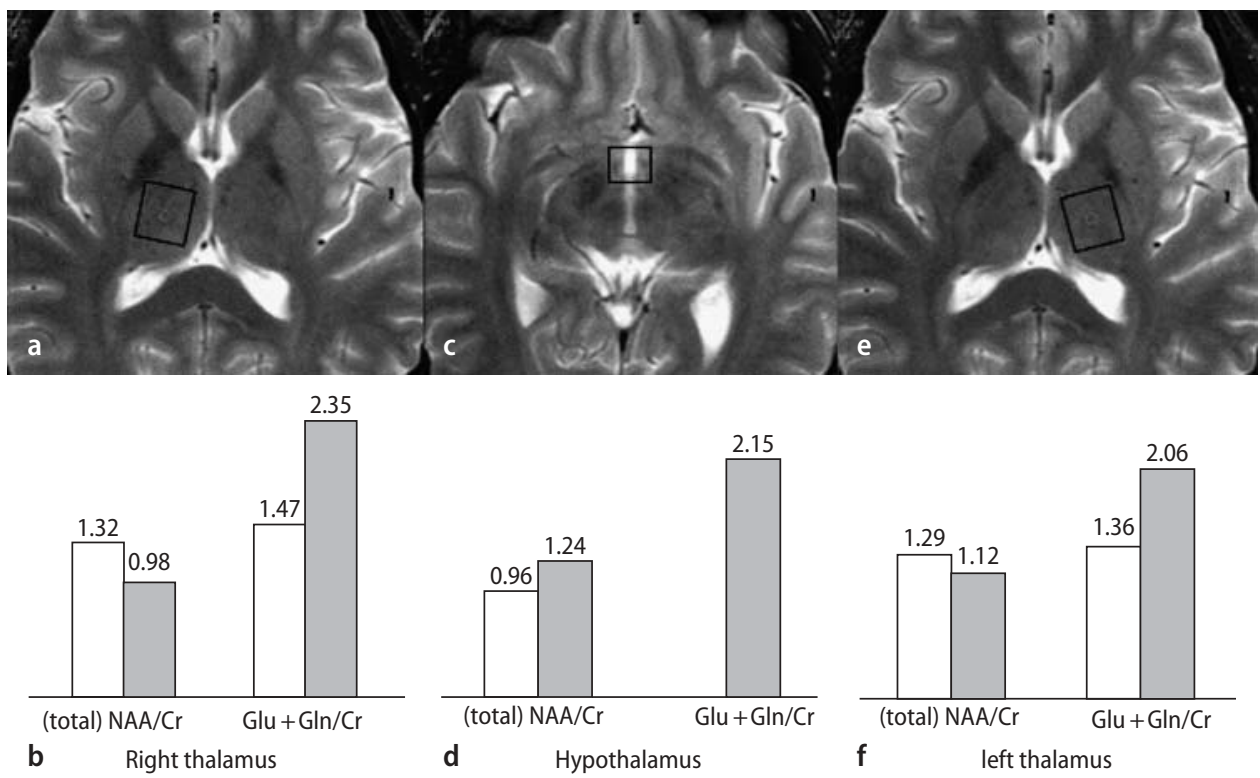

free of symptoms

hypersomnolent attack

$\mathrm{Glu}+\mathrm{Gln} / \mathrm{Cr}$ ratios have been reported in focal epilepsies in areas without structural abnormalities, linked to ictal and interictal epileptiform activities [9] as well as in the thalamus of patients with idiopathic generalised epilepsy, possibly related to excitotoxicity [10]. The neuronal pathophysiology of epilepsy is however different from that of KLS. The remarkable increase in Glu-Gln/Cr in our patient may account for a depolarisation block and post-excitatory suppression of various thalamic nuclei. A consequence of the large cortical projections of the thalamus may be that it leads to a widespread cortical suppression. As we report a single case, a confirmation of our hypothesis is needed.

Acknowledgments Dr. Pierluigi Pedrazzi, Hospital "San Giovanni" Bellinzona who kindly referred the patient.

\section{References}

1. Bassetti C, Billiard M, Mignot E, Arnulf I (2006) Kleine-Levin syndrome and other recurrent hypersomnia. In: Bassetti C, Billiard M, Mignot E (eds) Narcolepsy and hypersomnia. Dekker Publishing, NYC, NY, pp 89-95

2. Arnulf I, Zeitzer JM, File J, Farber N, Mignot E (2005) Kleine-Levin syndrome: a systematic review of 186 cases in the literature. Brain 128: 2763-2776

3. Huang YS, Guilleminault C, Kao PF, Liu FY (2005) SPECT findings in the Kleine-Levin syndrome. Sleep 28: 955-960

4. Hong SB, Joo EY, Tae WS, Lee J, Han SJ, Lee HW (2006) Episodic diencephalic hypoperfusion in Kleine-Levin syndrome. Sleep 29:1091-1093

5. Rubaek E, Ross D (1999) Magnetic resonance spectroscopy diagnosis of neurological diseases. Dekker Publishing, NYC, NY

6. Malhotra S, Das MK, Gupta N, Muralidharan R (1997) A clinical study of Kleine-Levin syndrome with evidence for hypothalamic-pituitary axis dysfunction. Biol Psychiatry 42:299-301
7. Wellard RM, Briellmann RS, Jennings C, Jackson GD (2005) Physiologic variability of single-voxel proton MR spectroscopic measurements at $3 \mathrm{~T}$. Am J Neuroradiol 26:585-590

8. Bassetti C, Mathis J, Gugger M, Lovblad KO, Hess CW (1996) Hypersomnia following paramedian thalamic stroke: a report of 12 patients. Ann Neurol 39:471-480

9. Guye M, Ranjeva JP, Le Fur Y, Bartolomei F, Confort-Gouny S, Regis J, Chauvel P, Cozzone PJ (2005) ${ }^{1} \mathrm{H}$-MRS imaging in intractable frontal lobe epilepsies characterized by depth electrode recording. Neuroimage 26:1174-1183

10. Helms G, Ciumas C, Kyaga S, Savic I (2006) Increased thalamus levels of glutamate and glutamine ( $\mathrm{Glx})$ in patients with idiopathic generalized epilepsy. J Neurol Neurosurg Psychiatry 77:489-494 